\title{
Design and performance Assessment of an Airborne Ice Sounding Radar Front-End
}

\author{
Hernández, Carlos Cilla; Krozer, Viktor; Vidkjær, Jens; Dall, Jørgen
}

Published in:

Microwaves, Radar and Remote Sensing Symposium, 2008

Link to article, DOI:

10.1109/MRRS.2008.4669596

Publication date:

2008

Document Version

Publisher's PDF, also known as Version of record

Link back to DTU Orbit

Citation (APA):

Hernández, C. C., Krozer, V., Vidkjær, J., \& Dall, J. (2008). Design and performance Assessment of an Airborne Ice Sounding Radar Front-End. In Microwaves, Radar and Remote Sensing Symposium, 2008: MRRS 2008 (pp. 284-288). Materials Research Society. https://doi.org/10.1109/MRRS.2008.4669596

\section{General rights}

Copyright and moral rights for the publications made accessible in the public portal are retained by the authors and/or other copyright owners and it is a condition of accessing publications that users recognise and abide by the legal requirements associated with these rights.

- Users may download and print one copy of any publication from the public portal for the purpose of private study or research.

- You may not further distribute the material or use it for any profit-making activity or commercial gain

- You may freely distribute the URL identifying the publication in the public portal 


\title{
Design and Performance Assessment of an Airborne Ice Sounding Radar Front-End
}

\author{
Carlos Cilla Hernández, Viktor Krozer, Jens Vidkjær, and Jørgen Dall \\ \# Technical University of Denmark \\ Ørsteds Plads 348 \\ 2800 Kongens Lyngby, Denmark \\ vk@elektro.dtu.dk
}

\begin{abstract}
The paper describes the design and experimental performance assessment of the RF front-end of an airborne Pband ice sounding radar. The ice sounder design features newly developed components at a centre frequency of $435 \mathrm{MHz}$, such as, antenna $20 \%$ bandwidth at $\mathrm{RL}<13 \mathrm{~dB}$, compact high power in-phase and out-of-phase power dividers with a relative bandwidth of $20 \%$ and more than $75 \mathrm{~W} \mathrm{CW}$ power handling, high power SPDT PIN switch with $90 \mathrm{~W} \mathrm{CW}$ power handling and a 70W CW High efficiency LDMOS power amplifier with $>60 \%$ power-added efficiency. The system comprises also a digital signal generator, a digital front-end and a control unit. The system was functionally tested in March 2008 and had a first successful proof-of-concept campaign in Greenland in May 2008.
\end{abstract}

\section{INTRODUCTION}

The European Space Agency has assigned the Technical University of Denmark (DTU) the development of an airborne P-band ice sounding radar demonstrator, hereinafter the "Psounder". The project will help to understand the behavior of ine at P-band and it will enuble the detecton of internal ice layers, reflection from the base of the ice sheet and validation of data processing algorithms for future satellite missions.

Key parameters of the instrument are listed in Table I and additional specifications and requirements are found in [1]. Fig. 1. shows the P-sounder installed on the Twin Otter aircraft.

TABLE I

P-SOUNDER SPECIFICATIONS

\begin{tabular}{|c|c|}
\hline Centre frequency & $\begin{array}{c}435 \\
\mathrm{MHz}\end{array}$ \\
\hline Bandwidth (goal) & $85 \mathrm{MHz}$ \\
\hline Polarization & Quad \\
\hline Maximum pulse length & $50 \mu \mathrm{s}$ \\
\hline Peak power & $120 \mathrm{~W}$ \\
\hline Maximum PRF & $20 \mathrm{kHz}$ \\
\hline Operating altitude & $3500 \mathrm{~m}$ \\
\hline
\end{tabular}

The system sensitivity is sufficient to detect the bedrock through $4 \mathrm{~km}$ of ice and pulse-to-pulse coherence helps improving the sensitivity. Surface clutter suppression is implemented with the help of synthetic aperture processing. The P-sounder features an experimental coherent clutter suppression capability based on a multiple-phase-centre antenna. The technique is similar to that of the MARSIS sounder [1]. Full polarimetry is justified by ice physics and special care is taken to achieve good calibration and stability [2]

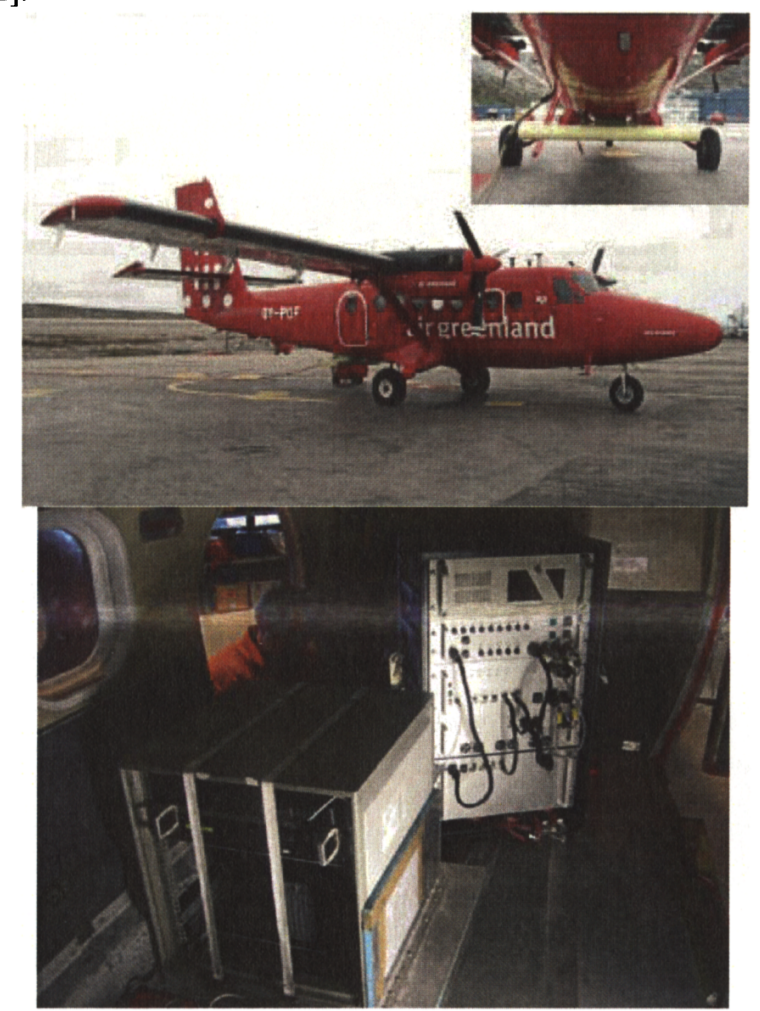

Fig. 1. Twin Otter aircraft with the antenna under the fuselage (left) and Psounder system mounted inside (right)

A system analysis based on the envisioned flight geometry, system specifications, and data processing suggests that a peak power of $100 \mathrm{~W}$ in combination with an antenna with four patches in the across-track direction is sufficient to detect the bedrock down to $4 \mathrm{~km}$. Based on very good experience with the airborne EMISAR system [3] the internal calibration is done by looping the generated pulses around as close to the antennas as possible and back through the receiver channel. This way the calibration is carried out in an almost perfect way by using exactly the same signal as used during normal operation.

The paper describes the design of the key RF components and shows preliminary measurements of the system. Additional 
information about the newly developed wideband probe-fed dual-linear polarisation wideband microstrip patch antenna array can be found in [4]. Both experimental results and simulations agree well in most cases for the individual components and the relative bandwidth requirement of $>20 \%$ is realized with most components.

\section{RF FRONT-END COMPONENTS}

The RF architecture is shown in Fig. 2. The transmitter is composed of a high power high-efficiency LDMOS amplifier, a high power SPDT PIN switch, a circulator, a slow high power relay for calibration and high power splitters. The receiver front-end is composed of a limiter, a low-noise amplifier, band pass filters and a variable gain amplifier that provides sufficient gain to drive optimally the $A / D$ converters in the digital acquisition unit.

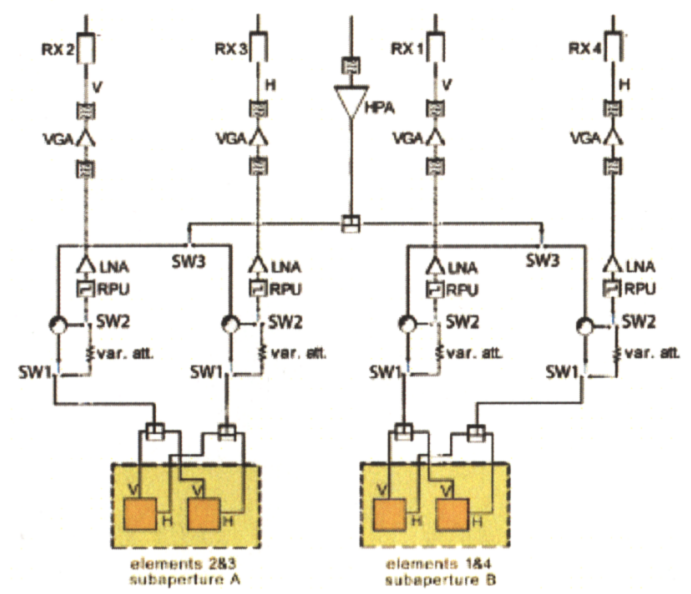

Fig. 2. RF Front-End architecture

\section{A. Power Dividers}

We have developed lumped element Wilkinson type inphase and out-of-phase power dividers. Such realizations have been presented earlier [5], [6], but did not have the RF power handling capabilities. Out-of-phase lumped element power dividers have also been reported earlier [7] including dividers using metamaterial lines [8]. The design here is based on metamaterial lines, but exhibits a better bandwidth performance and can handle higher powers with considerably less losses. Fig. 3 shows a photograph of the out-of-phase Wilkinson divider employing left-handed/right-handed sections to realize the $180^{\circ}$ phase shift between the ports 2 and 3 . The dimensions of both divider circuits are around $60 \mathrm{~mm} \times$ $40 \mathrm{~mm}$.

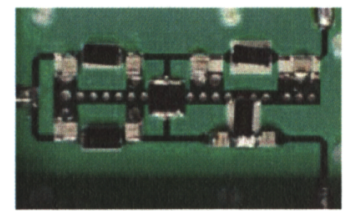

Fig. 3. Photograph of the fabricated $180^{\circ}$ lumped element Wilkinson divider.
The design is a compromise between amplitude and phase unbalance. The phase difference between the ports has been adjusted to the very small value of around $4^{0}$, at the expense of an amplitude unbalance of $0.23 \mathrm{~dB}$. The circuit inevitably exhibits higher losses as compared with the standard Wilkinson divider realized here (insertion loss $0.2 \mathrm{~dB}$ ), but the measured losses remain below $0.5 \mathrm{~dB}$, comparable to a $180^{\circ}$ coupler. The phase difference has a maximum measured variation of $2^{0}$, which is an excellent value and matches perfectly $180^{\circ}$ at the center frequency. Even better results, amplitude difference of $0.1 \mathrm{~dB}$, insertion loss of $0.2 \mathrm{~dB}$, phase balance $<1^{0}$ over the frequency band has been achieved for the in-phase lumped element Wilkinson divider. The necessary $20 \%$ bandwidth is realized for both circuits with a return loss better than $15 \mathrm{~dB}$ and power handling capabilities up to around $75 \mathrm{~W} \mathrm{CW}$ microwave power.
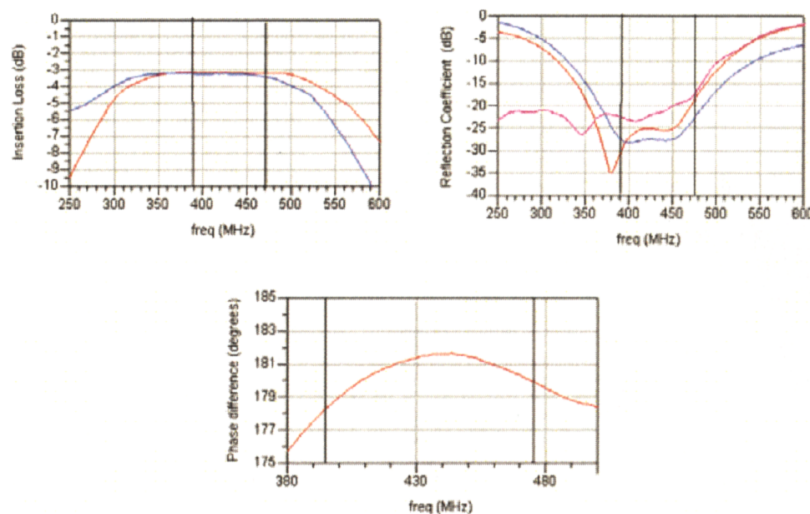

Tig. 4. Mcasured insertion loss, reflection coefficient and phase difference fo: the $180^{\circ}$ Wilkinson divider

\section{B. High Efficiency Power Amplifier}

Solid-state high power amplifiers (HPA) with the required output peak power $>100 \mathrm{~W}$ and the bandwidth of $80 \mathrm{MHz}$ at the frequency of operation are available from a very limited number of suppliers on a custom made basis and at a very high price. Therefore, we have developed a high efficiency power amplifier based on a proprietary design with $70 \mathrm{~W} \mathrm{CW}$ output power, $0.1 \mathrm{~dB} 395-475 \mathrm{MHz}$ bandwidth, high PAE of up to $68 \%$ and with a $28 \mathrm{~V}$ bias voltage.

The design operates on class $\mathrm{B}$ and the series tuning is preferred over parallel tuning due to the low impedance levels. The design is based on two stages, a driver and a power stage. Both stages have been initially designed, fabricated and measured separately. Afterwards, the stages have been combined successfully and the final amplifier fabricated on a FR4 professional board is shown in Fig. 5.

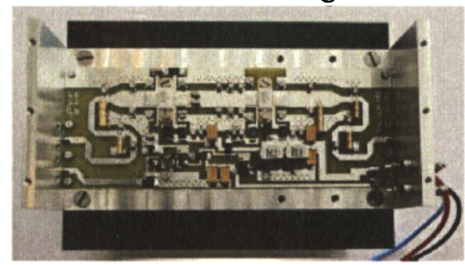

Fig. 5. High-efficiency power amplifier for P-Band $(84 \times 154 \times 35 \mathrm{~mm})$ 
A comparison between measured and simulated transducer gain and input reflection for the final design indicate that our predictions are rather reliable, as indicated in Figure 6. Both measured parameters are in excellent agreement with simulated results using the Freescale LDMOS model. In the operating range of the radar the HPA exhibits an input return loss of $>11 \mathrm{~dB}$ and a total $38.9 \mathrm{~dB}$ gain. Measurements of the output power, efficiency and transducer gain are shown in table II for the frequencies of interest with $9.6 \mathrm{dBm}$ input power.

Transducer Gain

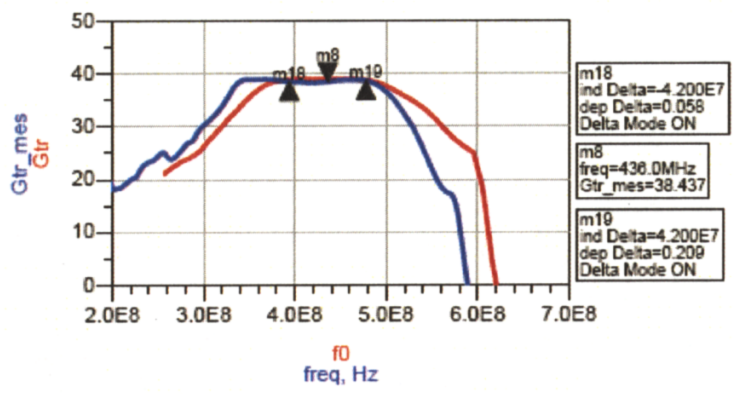

Input Reflection

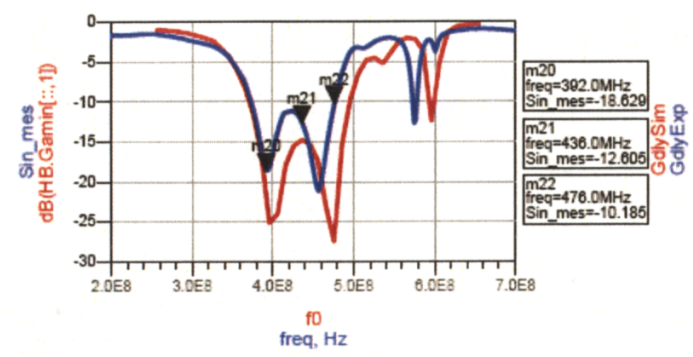

Fig. 6. Measured and simulated gain and return loss of the power amplifier.

TABLE III

HPA MEASUREMENTS WITH 9.6DBM INPUT POWER.

\begin{tabular}{|c|c|c|c|}
\hline $\begin{array}{c}\text { Freq } \\
(\mathbf{M H z})\end{array}$ & $\begin{array}{c}\text { Power } \\
(\mathbf{W})\end{array}$ & $\begin{array}{c}\text { Eff. } \\
(\%)\end{array}$ & $\begin{array}{c}\text { Gain } \\
(\mathbf{d B})\end{array}$ \\
\hline 395 & 70.87 & 69.9 & 38.905 \\
\hline 435 & 71.39 & 68.8 & 38.436 \\
\hline 475 & 70.87 & 69.9 & 38.905 \\
\hline
\end{tabular}

The radar front-end transmitter uses two of these power amplifiers modules in parallel to provide $>100 \mathrm{~W}$ peak power. The bias of both amplifiers has been carefully adjusted to obtain amplifiers with equal gain at the cost of reducing the efficiency to $60 \%$. The measured power at the output of the power combiner is $128.8 \mathrm{~W} \mathrm{CW}$ at $435 \mathrm{MHz}$. The gate of the power amplifiers can be switched on and off in order to improve the power dissipation capabilities and reduce the noise level generated during reception.

\section{High Power SPDT PIN Switch}

Due to the lack of commercially available switches combining high power handling capabilities and a relatively high switching speed, a SPDT PIN switch driven by a fast
TTL control circuit has been developed. The design is shown in Fig. 7, where a physical separation between the two RF branches and the driven circuit ensures high isolation at high power levels. The topology selected allows a trade-off between insertion loss and isolation, and consists of two shunted PIN diodes in each branch separated by a $\lambda / 4$ lumped section [11]. Two PIN diode simulation models have been successfully used in ADS during the design stage: one to simulate the RF performance [12] and the other to predict the switching time [13]. Furthermore ultra fast MOSFET transistors and drivers have been used in the control circuit design. Fig. 8 shows that the measured return loss at the three ports is better than $15 \mathrm{~dB}$, the insertion loss is lower than $0.6 \mathrm{~dB}$ and the isolation is better than $42.5 \mathrm{~dB}$ across the full band.

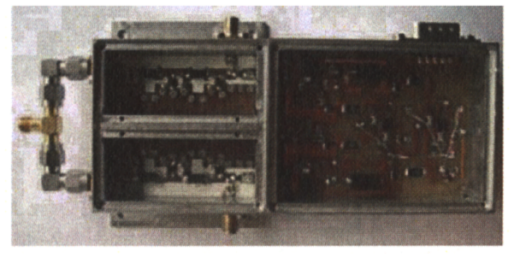

Fig. 7. RF PIN diode switch and fast driver circuit
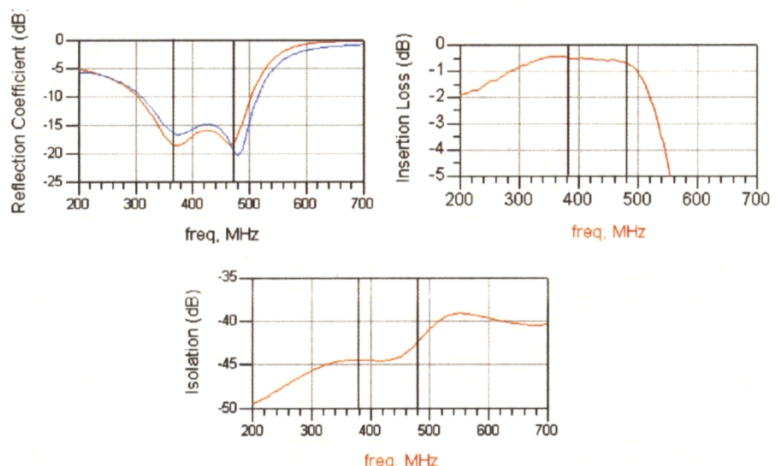

Fig. 8. Measured reflection coefficient, insertion loss, and isolation of the high power SPDT PIN switch.

The switching time measurements shown in Fig. 9. have been performed using a $435 \mathrm{MHz} 90 \mathrm{~W} \mathrm{CW}$ signal at the input. The measured delay time is $8 \mu \mathrm{s}$, and it agrees well with the simulated values in Agilent ADS. The switch-on time is $500 \mathrm{~ns}$ and the switch-off time $300 \mathrm{~ns}$. Furthermore, it is important to highlight that high voltage switching transients are not observed.

\section{System measurements}

The receiver chain test results with a $435 \mathrm{MHz}-45 \mathrm{dBm}$ signal at the input of the LNA are shown in Fig. 10. It can be observed that the return loss is better than $25 \mathrm{~dB}$ and the overall gain of the receiver is programmed with the variable gain amplifier to be $41 \mathrm{~dB}$ to drive the $\mathrm{A} / \mathrm{D}$ converters optimally. The noise figure is deteriorated by the limiter placed in front of the LNA, but it is still lower than $2.6 \mathrm{~dB}$. The PIN diode limiter is needed to protect the receiver during the transmission of high power pulses, and it also deteriorates the recovery time of the receiver. This is the time until the 
receiver recovers its normal sensitivity after an overvoltage at the input of the limiter. Fig.11 shows the recovery time measured with an oscilloscope. The channel on the foreground is the result of combining a $-45 \mathrm{dBm} \mathrm{CW}$ signal and a pulsed signal that activates the limiter, and the channel on the background is the output of the receiver. It is possible to observe that the evolvent of the receiver output is distorted during $800 \mathrm{~ns}$, but the time that the receiver is completely blind is only around $160 \mathrm{~ns}$.
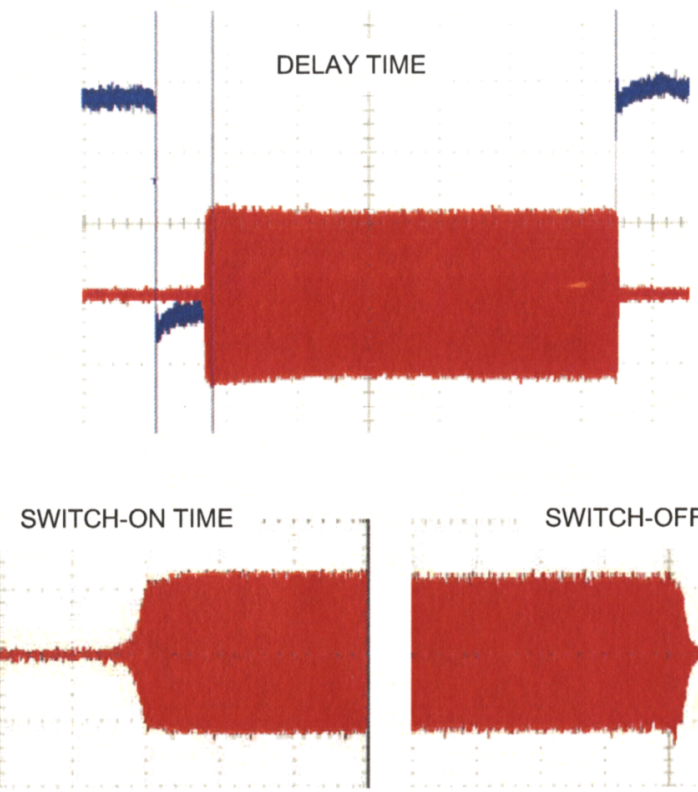

SWITCH-OFF TIME

Fig. 9. Measured delay time $(8 \mu \mathrm{s})$, switch-on time $(0.5 \mu \mathrm{s})$ and switch-off time $(0.3 \mu \mathrm{s})$ of the high power SPDT PIN switch. (RF signal in red and TTL control signal in blue).

Other measurements and laboratory tests of the transmitter in combination with the digital signal generator will be shown during the presentation.

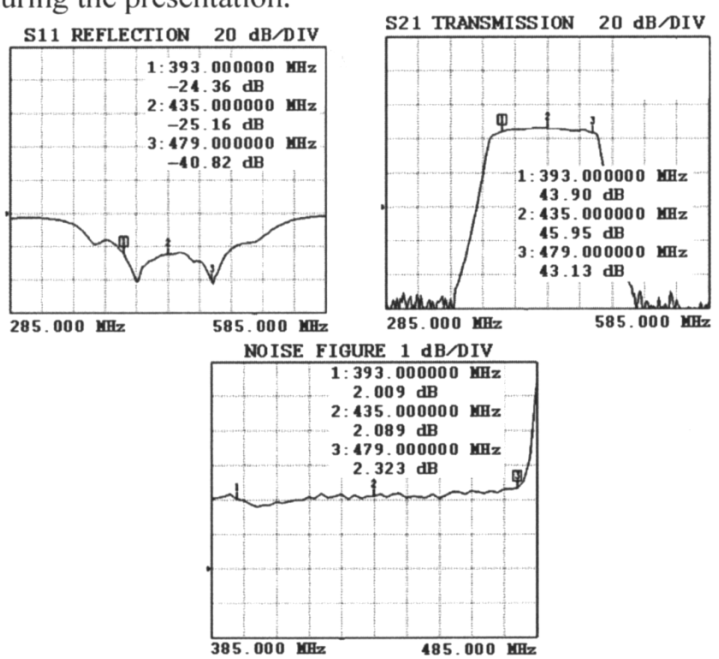

Fig. 10. Measured reflection coefficient, gain and noise figure of the receiver chain.

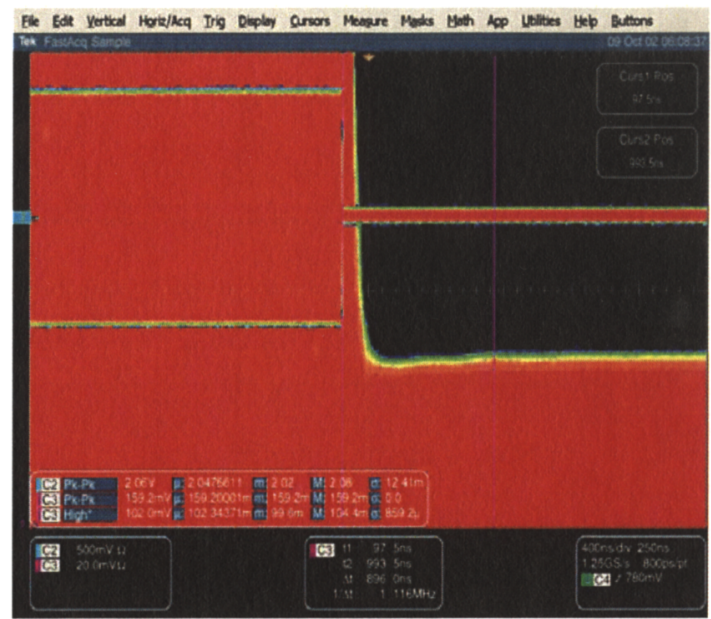

Fig. 11. Measured receiver recovery time (right)

\section{CONCLUSIONS}

We have presented component design for a P-band ice sounding radar. The relative bandwidth of all components is around $20 \%$ at a return loss level of $\mathrm{RL}>15 \mathrm{~dB}$. The $\mathrm{RF}$ components developed for the instrument are power dividers a high power amplifier and a high power SPDT PIN switch. Results for some of these components presented in the paper demonstrate the successful implementation of the design.

The lumped element Wilkinson dividers based on lefthanded/right-handed sections presented in this paper exhibit wideband operation with low measured and simulated losses of $<0.5 \mathrm{~dB}(0.2 \mathrm{~dB}$ for a standard lumped element Wilkinson divider) and good port matching. Phase unbalance between the ports in both circuits is $4^{\circ}$ and $2^{\circ}$, respectively. All these results are maintained during high power operation up to the tested power levels of $75 \mathrm{~W}$.

The HPA exhibits $>60 \%$ PAE at $70 \mathrm{~W}$ output power over the required bandwidth. This performance is achieved by series matching to the low terminal impedances in class B operation. The driver stages and the narrowband version of the HPA both exhibit PAE approaching $70 \%$. The driver and the HPA have good return loss and a constant gain across the frequency range. The driver gain varies only by $0.5 \mathrm{~dB}$ across the band and over the full power range. Excellent agreement is achieved between measurements and simulations in this case.

The high power SPDT PIN switch controlled by a $3.3 \mathrm{~V}$ TTL input signal presents a return loss better than $15 \mathrm{~dB}$, an insertion loss lower than $0.6 \mathrm{~dB}$ and an isolation $>42.5 \mathrm{~dB}$. The delay time is $8 \mu \mathrm{s}$, the switch-on time $0.5 \mu$ s and the switchoff time $0.3 \mu \mathrm{s}$. A good agreement between the simulations using ADS and measurements was observed both for the RF design and the fast driver performance. Power handling capability up to $90 \mathrm{~W} \mathrm{CW}$ was tested successfully.

\section{ACKNOWLEDGMENT}

The partial financial support by the European Space Agency under contract no. $19307 / 05 / \mathrm{NL} / \mathrm{JA}$ is acknowledged by the authors. 


\section{REFERENCES}

[1] G. Picardi, D. Biccari, R. Seu, L. Marinangeli, W.T.K. Johnson, R.L Jordan, J. Plaut, A. Safaenili, D.A. Gurnett, G.G. Ori, R. Orosei, D. Calabrese, E. Zampolini, "Performance and surface scattering models for the Mars Advanced Radar for Subsurface and Ionosphere Sounding (MARSIS)", Planetary and Space Science, Elsevier, No. 52, 2004.

[2] J. Dall, N. Skou, A. Kusk, S. S. Kristensen, V. Krozer, "Design of an airborne P-band ice sounding radar", Proc. Workshop on Advanced RF Sensors for Earth Observation 2006, Noordwijk, The Netherlands, Dec. 2006

[3] E. L. Christensen, N. Skou, J. Dall, K. Woelders, J. H. Jorgensen, J. Granholm, and S. N. Madsen, EMISAR: An Absolutely Calibrated Polarimetric L- and C-band SAR, IEEE Trans. Geoscience and Remote Sensing, vol. 36, no. 6, pp. 1852--1865, Nov. 1998.

[4] V. Krozer, C. Cilla, J. Vidkjær and J. Dall, "Development of an Airborne Ice Sounding Radar Front-End”, European Microwave Week, October 2007.

[5] T. Hirota, A. Minakawa, and M. Muraguchi, "Reduced-size branchline and rat-race hybrids for uniplanar MMIC's," MicrowaveTheory and Techniques, IEEE Transactions on, vol. 38, no. 3, pp. $270-275$ 1990.
[6] M. Chongcheawchamnan, N. Siripon, and I.D. Robertson, "Design and performance of improved lumped-distributed Wilkinson divider topology," Electronics Letters, vol. 37, no. 8, pp. 501 -503, 2001

[7] H.S. Nagi, "Miniature lumped element 180/spl deg/ Wilkinson divider," 2003 IEEE MTT-S Microwave Symposium Digest, vol. 1, pp. 55-58 vol.1, 2003.

[8] M.A. Antoniades and G.V. Eleftheriades, "A Broadband Wilkinson Balun Using Microstrip Metamaterial Lines," IEEE Antennas and Wireless Propagation Letters, vol. 4, no. 1, pp. 209-212, 2005

[9] Steven C. Cripps, Advanced Techniques in RF Power Amplifier Design Artech House Publishers, 2002

[10] Thomas Soerensen Yassin, "Development and Manufacturing of Direct Antenna Integrated RF Front- End for Ice Sounding Radar," M.S thesis, Electromagnetic Systems, TU Denmark, Kgs. Lyngby, Denmark, 2006

[11] G. Hiller, "Design with PIN diodes", MA-COM Application Note

[12] J. Walston, "Spice circuit yields recipe for pin diode", Microwaves \& Amp; RF, vol. 31, no.11, pp 78,82,85,87, 1992

[13] M. Andersson, "An advance PIN-diode Model", Microwave Journal, September 2005, pp. 206-212. 